\title{
Enhancement of the short-term probability of large earthquakes with a foreshock model and verification test
}

\author{
Masajiro Imoto \\ National Research Institute for Earth Science and Disaster Prevention, 3-1 Tennodai, Tsukuba-shi, Ibaraki-ken 305-0006, Japan
}

(Received November 28, 2003; Revised June 1, 2004; Accepted June 10, 2004)

\begin{abstract}
This study attempts to estimate the short-term probabilities of large earthquakes in an offshore area of northeast Japan, where long-term probabilities are assessed based on earthquake intervals. Previous studies report foreshock activity in the area, which could be used for the estimation. From this point of view, a hazard function was constructed based on the concept of "potential foreshocks" of the study area. A total of 14 earthquakes that occurred between 1976 and 2000 are employed in an assessment of models. The probability of a target earthquake occurring at a point in the time-space domain depends on the number of small earthquakes in the vicinity of the point. The parameters for defining potential foreshocks are magnitude, spatial extent, and lead-time to the point, which is optimized by a maximum probability procedure. The most effective hazard function is achieved based on foreshocks of magnitude 4.5 and larger within 1 day and $20 \mathrm{~km}$. A maximum probability gain of more than 20,000 is obtained if there are two or more foreshocks. We started verification tests applying the model to data from January 1, 2001 to date, but conclusive results were not yet obtained due to the small sample size of target events.
\end{abstract}

Key words: Short-term probability, foreshock, test, hazard, Tohoku, Miyagi-oki.

\section{Introduction}

Long-term earthquake probabilities for the offshore area of the Tohoku district on the Pacific Ocean side were estimated by Earthquake Research Committee, Government of Japan $(2000,2002)$, where the probabilities of earthquake occurrences within a few decades are discussed. Some high probabilities were found for the area off Miyagi, and other areas. It is desirable to estimate mid-term and/or short-term probabilities for such areas. Although there is presently no generally accepted method for mid- or short-term predictions, a probability prediction technique using the sequence of a large earthquake ( $M \geq 6.0)$ was attempted in the off Miyagi region (Meteorological Res. Inst., 1993). The reported case revealed a probability of some tens of percent that a large earthquake would be followed by another large event. Maeda (1996) reported foreshock activity in the region and obtained an additional probability gain of 50 to 600 . Considering these features of clustering characteristic in this region, Imoto (2003) proposed a simple procedure to enhance the short-term probability estimate in respective regions, where all events within a certain space and time window (referred to as "Potential foreshocks") would be followed by a large earthquake with a certain probability (calculated using past data). Short-term earthquake probability can be enhanced over the estimated long-term probability in the manner described by Utsu $(1977,1982)$ and Aki (1981) for the case of multiple independent precursors. Improvements to earthquake probability calculations are addressed in a previous paper (Imoto, 2003), which considers the po-

Copy right (c) The Society of Geomagnetism and Earth, Planetary and Space Sciences (SGEPSS); The Seismological Society of Japan; The Volcanological Society of Japan; The Geodetic Society of Japan; The Japanese Society for Planetary Sciences; TERRAPUB. tential foreshock to be an example of precursory phenomena, combined with the long-term probability. The performance of the proposed model is evaluated by the usual optimization procedure to fit the past data. A bias, unconsciously introduced by the author might cause the performance of the model to be overestimated (Console and Murru, 2001). An objective test using independent data from those used in model construction should be undertaken to verify the model (Rhoades and Evison, 1989; Evison and Rhoades, 1997).

In this paper, we outline the potential foreshock model, where basic parameters for obtaining enhanced short-term probabilities will be given, and discuss results of verification tests obtained up to the present, including activities of the $M=8.0$ Tokachi-oki earthquake, Hokkaido, Japan, on 26 September 2003.

\section{Potential Foreshock}

We consider an earthquake $\left(M \geq M_{f}\right)$ that occurs within $T_{f}$ days and the spherical volume of a $R_{f} \mathrm{~km}$ radius, centered at a point of interest, as a potential foreshock, and the number of potential foreshocks is referred to as $N_{f}$. The times of occurrence and hypocentral locations of the main shocks constitute the point process, and we define a hazard function containing the number $N_{f}$ of potential foreshocks as a variable. Considering that there are more potential foreshocks before a large earthquake than other will and that these correspond to two stages in seismic activity, both of which are well represented by a Poisson process with different constants, Imoto (2003) gives the hazard function, $\lambda\left(s \mid N_{f}\right)$ at point $s$ of the form:

$$
\begin{aligned}
\lambda\left(s \mid N_{f}\right)=\alpha \times \beta^{j} j & =N_{f} ; 0 \leq N_{f}<N_{c} \\
j & =N_{c} ; N_{c} \leq N_{f}
\end{aligned}
$$


a

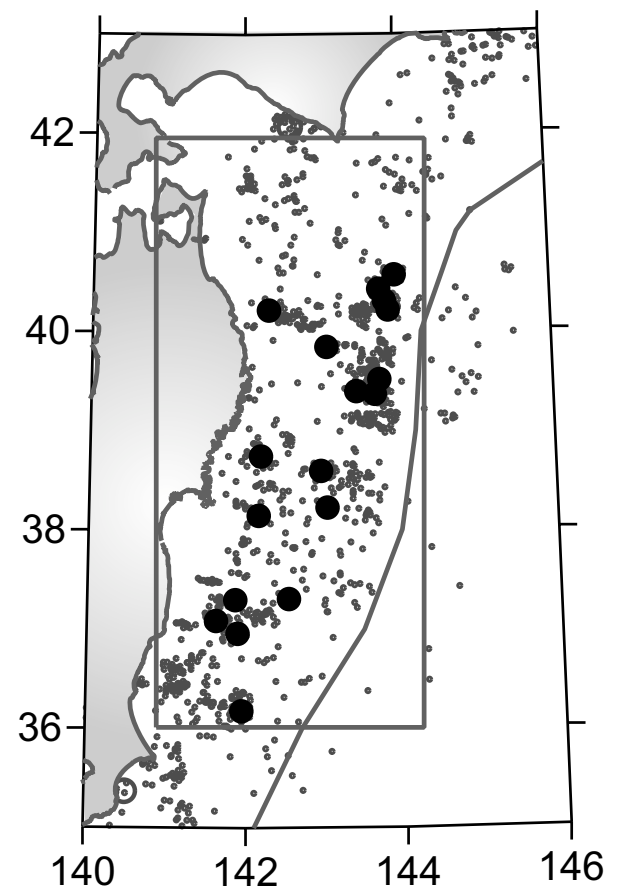

b

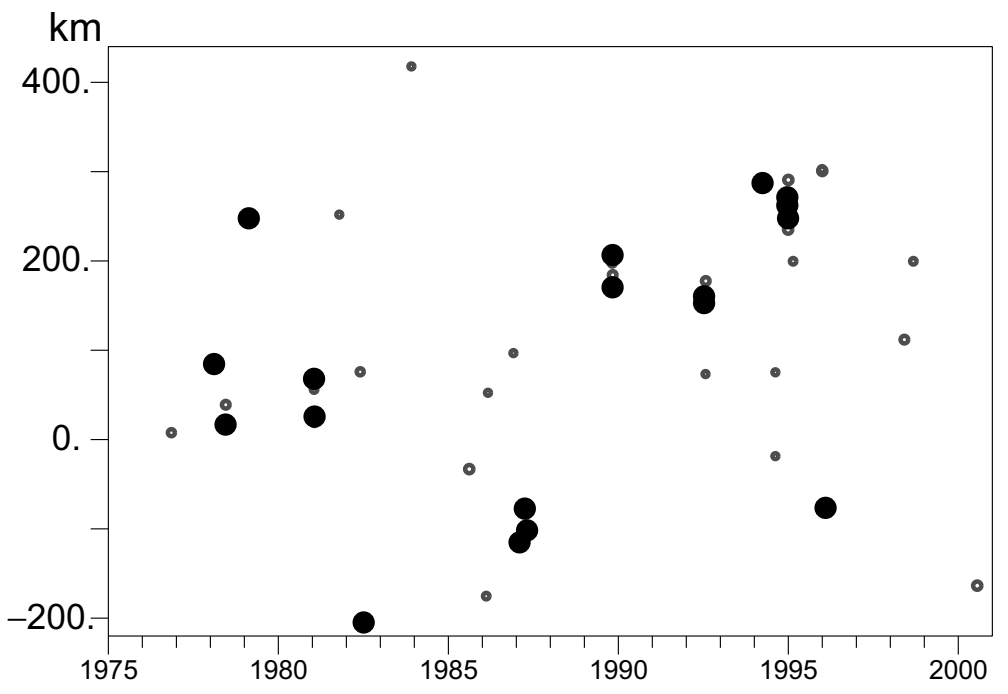

Fig. 1. (a) Epicenter map of target events with $M \geq 6.5$, and events with magnitudes $\geq 4.5$ (small circles). The box indicates the study area. (b) Space and time plots of target events (large circles), and major events of $6.5>M \geq 6.0$ (small circles). The ordinate indicates the north-south distance in km.

where an upper limit of the power component in Eq. (1) is introduced to achieve a reliable hazard function (Imoto, 2003). The estimation of upper limit $N_{c}$ is optimized by a grid search method together with parameters $M_{f}, R_{f}$, and $T_{f}$.

The likelihood function $L_{p}$ is given by

$$
L_{p}=\exp \left\{-\int \lambda\left(s \mid N_{f}\right) d s\right\} \times \prod \lambda\left(s_{i} \mid N_{f i}\right)
$$

where $\lambda\left(s_{i} \mid N_{f i}\right)$ is the value of the hazard function at $s_{i}$, the time and location of the occurrence of the $i$-th earthquake. Substituting (1) into Eq. (2), the coefficients $\alpha, \beta$ are determined by the maximum likelihood method. The goodnessof-fit of statistical models can be compared using the Akaike information criterion (AIC) (e.g., Sakamoto et al., 1983). $A I C$ is defined by the following formula from the maximum likelihood:

$$
A I C=-2 \cdot \ln L+2 . \times m
$$

where $m$ is the number of model parameters. The values of $A I C$ calculated from Eq. (2), and stationary Poisson models are referred to as $A I C_{1}$ and $A I C_{0}$; the difference, $d A I C$, is defined by the following equation.

$$
d A I C=A I C_{0}-A I C_{1} .
$$

The effectiveness of the earthquake probability calculated from the hazard function of Eq. (1) can be measured by dAIC (Imoto, 2001).

\section{Optimal Model}

The present study employs the earthquake catalogue provided by the Japan Meteorological Agency. The study area covers the time-space domain to the offshore area west of the Japan Trench (east-west $300 \mathrm{~km}$, north-south $660 \mathrm{~km}$, and depth 0-60 km) from 1976 to 2000 (Fig. 1). Earthquakes with magnitudes 6.5 and greater were adopted as the target events (hereafter referred to as the main shocks), balancing a lower cutoff magnitude that achieves more reliable results with a increased number of main shocks and a higher cutoff magnitude that reduces the chance of aftershock contamination of the main shocks. Imoto (2003) studied other cases using different criteria for main shocks and obtained results similar to the present one in terms of effectiveness of the hazard function. Eighteen earthquakes with magnitudes of 6.5 and greater have occurred in this domain (Table 1). The duration times of observing respective numbers of potential foreshocks, $N_{f}(=0,1,2 \ldots)$, were calculated at each lattice point with a $10 \mathrm{~km}$ spacing in three space dimensions and summed respectively to establish the background density distribution of $N_{f}$. A conditional density distribution of $N_{f}$ was obtained from the $N_{f}$ value prior to each main shock at its hypocenter. A total of 25 cases, five cases of $R_{f}$ (every $20 \mathrm{~km}$; range of 20 to $100 \mathrm{~km}$ ) by five cases of $T_{f}$ (day by day; range of 1 to 5 days), were calculated here for $M_{f}=4.0,4.5$, and 5.0.

Figure 1 illustrates the time-space plots of earthquakes. The main shock is represented by a large symbol. The small circles in Fig. 1(a) indicate earthquakes with magnitudes exceeding 4.5. The rectangle represents the study area. Figure 1(b) depicts a space-time plot, where the ordinate is the north-south distance in $\mathrm{km}$. Small circles in the figure indicate earthquakes with magnitudes of 6.0 to 6.5. We observed clusters of earthquakes that contained main shocks in a few cases. Two or more earthquakes of $6.5 \leq M$ in- 
Table 1. Main shocks with $M \geq 6.5$. Asterisks denote target events.

\begin{tabular}{|c|c|c|c|c|c|c|c|c|c|c|}
\hline \multirow[b]{2}{*}{ No } & \multicolumn{4}{|c|}{ OriginTime } & \multicolumn{3}{|c|}{ Location } & \multirow[t]{2}{*}{ Mag } & \multirow[t]{2}{*}{$\mathrm{Nf}$} & \\
\hline & Date & $\mathrm{H}$ & $\mathrm{M}$ & $\mathrm{S}$ & Lat. & Long. & Depth & & & \\
\hline 1 & 20-Feb-78 & 13 & 36 & 5.7 & 38.75 & 142.20 & 50 & 6.7 & 0 & * \\
\hline 2 & 12-Jun-78 & 17 & 14 & 2.5 & 38.15 & 142.17 & 40 & 7.4 & 1 & * \\
\hline 3 & 20-Feb-79 & 15 & 32 & 3.3 & 40.22 & 143.87 & 0 & 6.5 & 0 & * \\
\hline 4 & 19-Jan-81 & 3 & 17 & 2.4 & 38.60 & 142.97 & 0 & 7.0 & 2 & * \\
\hline 5 & 23-Jan-81 & 4 & 34 & 4.0 & 38.23 & 143.05 & 0 & 6.6 & 0 & \\
\hline 6 & 23-Jul-82 & 23 & 23 & 5.1 & 36.18 & 141.95 & 30 & 7.0 & 3 & * \\
\hline 7 & 06-Feb-87 & 22 & 16 & 1.5 & 36.96 & 141.90 & 35 & 6.7 & 2 & * \\
\hline 8 & 07-Apr-87 & 9 & 40 & 4.3 & 37.30 & 141.87 & 44 & 6.6 & 0 & * \\
\hline 9 & 23-Apr-87 & 5 & 13 & 2.3 & 37.09 & 141.63 & 46.1 & 6.5 & 0 & * \\
\hline 10 & 29-Oct-89 & 14 & 25 & 3.8 & 39.52 & 143.74 & 0 & 6.5 & 2 & * \\
\hline 11 & 02-Nov-89 & 3 & 25 & 3.3 & 39.85 & 143.06 & 0 & 7.1 & 0 & * \\
\hline 12 & 18-Jul-92 & 17 & 36 & 5.6 & 39.37 & 143.68 & 0 & 6.9 & 3 & * \\
\hline 13 & 18-Jul-92 & 17 & 39 & 0.2 & 39.40 & 143.44 & 0 & 6.9 & 3 & \\
\hline 14 & 08-Apr-94 & 10 & 10 & 4.1 & 40.57 & 143.96 & 2 & 6.5 & 0 & * \\
\hline 15 & 28-Dec-94 & 21 & 19 & 2.1 & 40.43 & 143.75 & 0 & 7.6 & 0 & * \\
\hline 16 & 29-Dec-94 & 7 & 37 & 4.9 & 40.31 & 143.82 & 8 & 6.5 & 4 & \\
\hline 17 & 07-Jan-95 & 7 & 37 & 37.2 & 40.22 & 142.31 & 47.8 & 7.2 & 0 & \\
\hline 18 & 17-Feb-96 & 0 & 22 & 58.2 & 37.31 & 142.55 & 58 & 6.8 & 0 & * \\
\hline
\end{tabular}

Table 2. Comparisons of $d A I C$ values for different $M_{f}$ values.

\begin{tabular}{l|ll} 
Sample & dAIC & dAIC/N(=14) \\
\hline \hline $\mathrm{M} \geq 4$ & 86.4 & 6.17 \\
$\mathrm{M} \geq 4.5$ & 98.8 & 7.06 \\
$\mathrm{M} \geq 5$ & 96.01 & 6.86
\end{tabular}

Table 3. Maximum probability gains (upper) and dAIC values (lower) for different $R_{f}$ and $T_{f}$ values, where $M_{f}=4.5$.

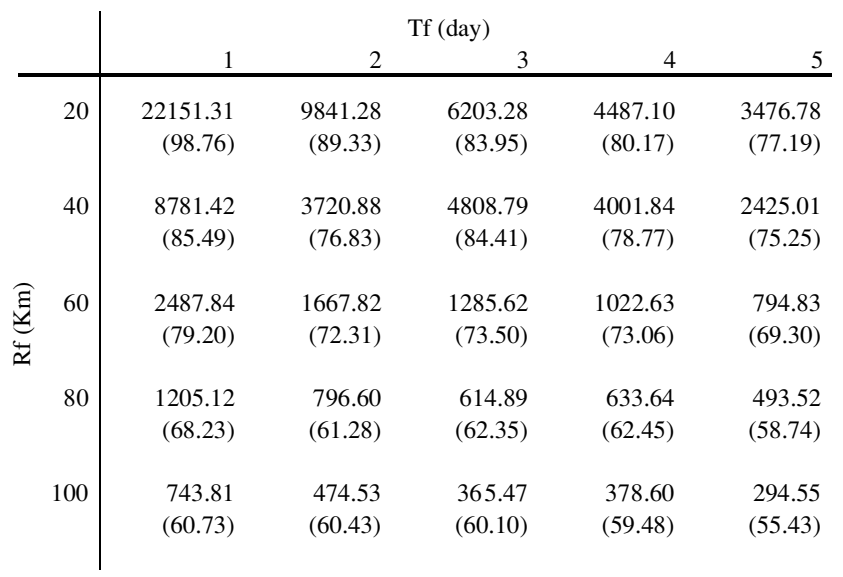

cluded in a cluster (hypocentral distance less than $50 \mathrm{~km}$, and interval less than two weeks) were regarded as a multiple event or swarm activity, and only the first event was chosen as the main shock. Thus, fourteen main shocks are selected (marked by asterisks in Table 1).

Table 2 summarizes the analysis result. Three types were distinguished by the difference in $M_{f}$. The $d A I C$ value and the value divided by the number of main shocks are listed for each case. The latter is related to the average probability gain (Imoto, 2001). This parameter is generally six or seven for different $M_{f}$ 's; there were no significant differences among the cases in terms of average probability gain. Thus we shall hereafter consider number of main shocks, reliability, and other factors only for $M_{f}=4.5$. Table 3 lists the maximum probability gain (the upper row) and $d A I C$ (the lower, with

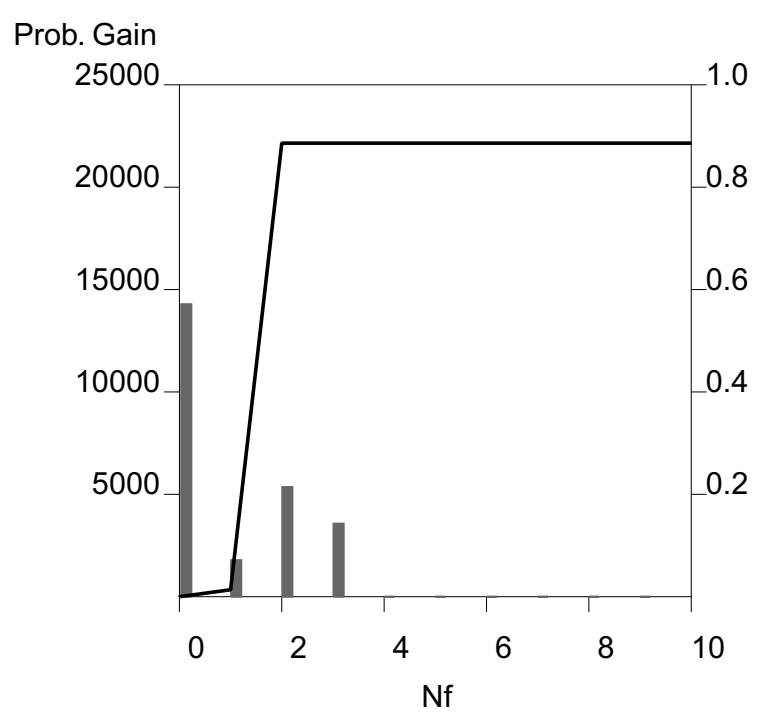

Fig. 2. The hazard function proposed here. The hazard (solid line) is given relative to the rate for the stationary Poisson process model (probability gain; scale at the left). The histograms indicate the probability distribution for $N_{f}$ values (scale at the right). $R_{f}=20, T_{f}=1$.

parentheses) for 25 different $R_{f}$ and $T_{f}$ values. The greatest $d A I C$ was observed for $R_{f}=20, T_{f}=1$, where the maximum probability gain exceeds 20,000 . A probability gain of about 5,000 is expected even for $R_{f}=40, T_{f}=3$, which is the fourth best case. The hazard related to $N_{f}$ in the best case is indicated in Fig. 2. The ordinate (left side) indicates the probability gain (i.e., the hazard in a unit of the Poisson rate). The conditional distribution (relative frequency) is drawn by histograms for reference (scale at the right in the figure). The hazard function is given in the form of Eq. (1), and thus a substantial probability gain will be obtained for a large $N_{f}$. In the present case, as the optimal value of $N_{c}$ being 2 , when we observe two or more potential foreshocks, the largest probability gain of more than 20000 can be obtained. 

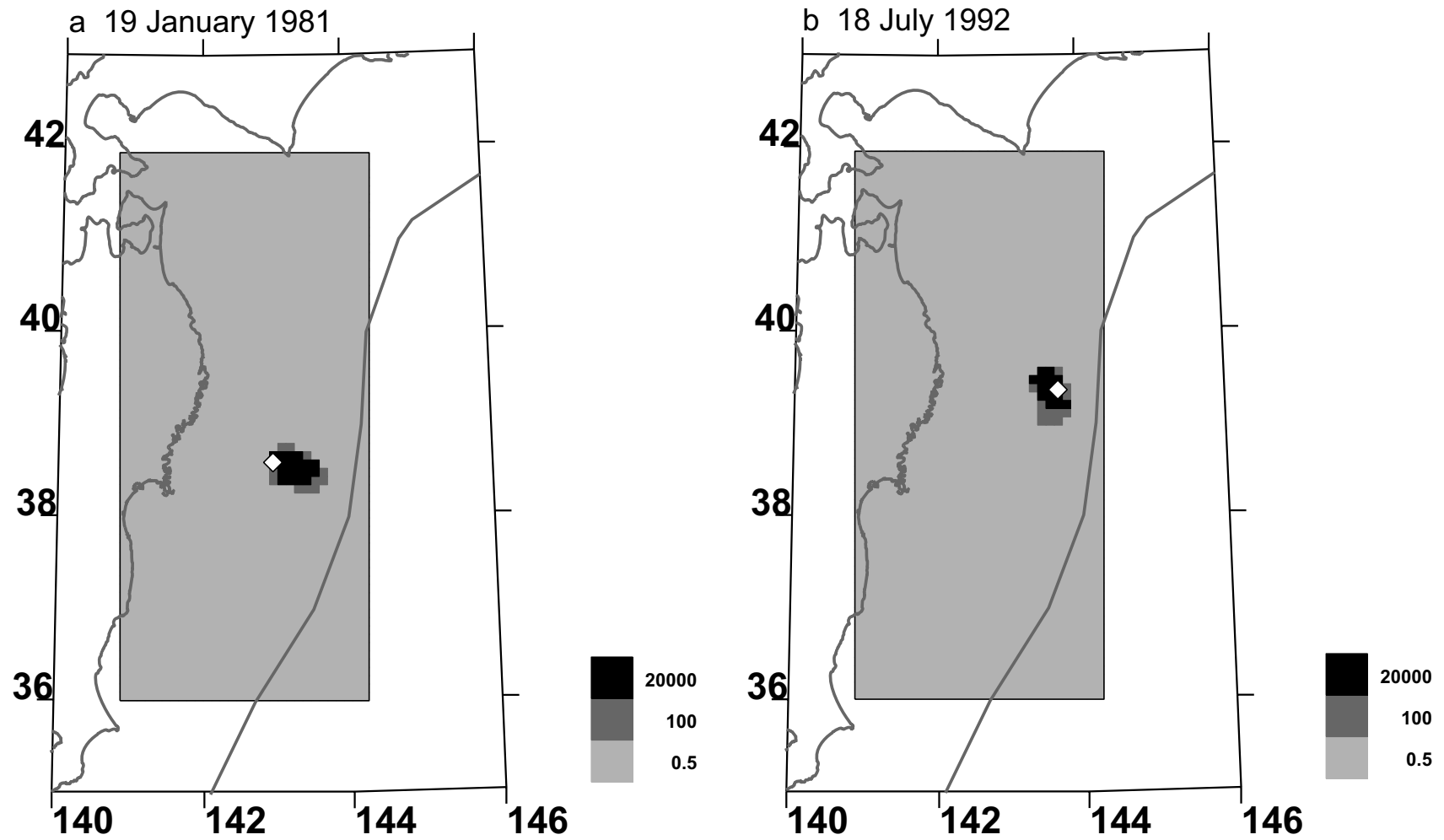

Fig. 3. Spatial distribution of the hazard in terms of probability gain before two events. The epicenter of the target event is represented by a dot in the respective sets. a) 19 January 1981. b) 18 July 1992.

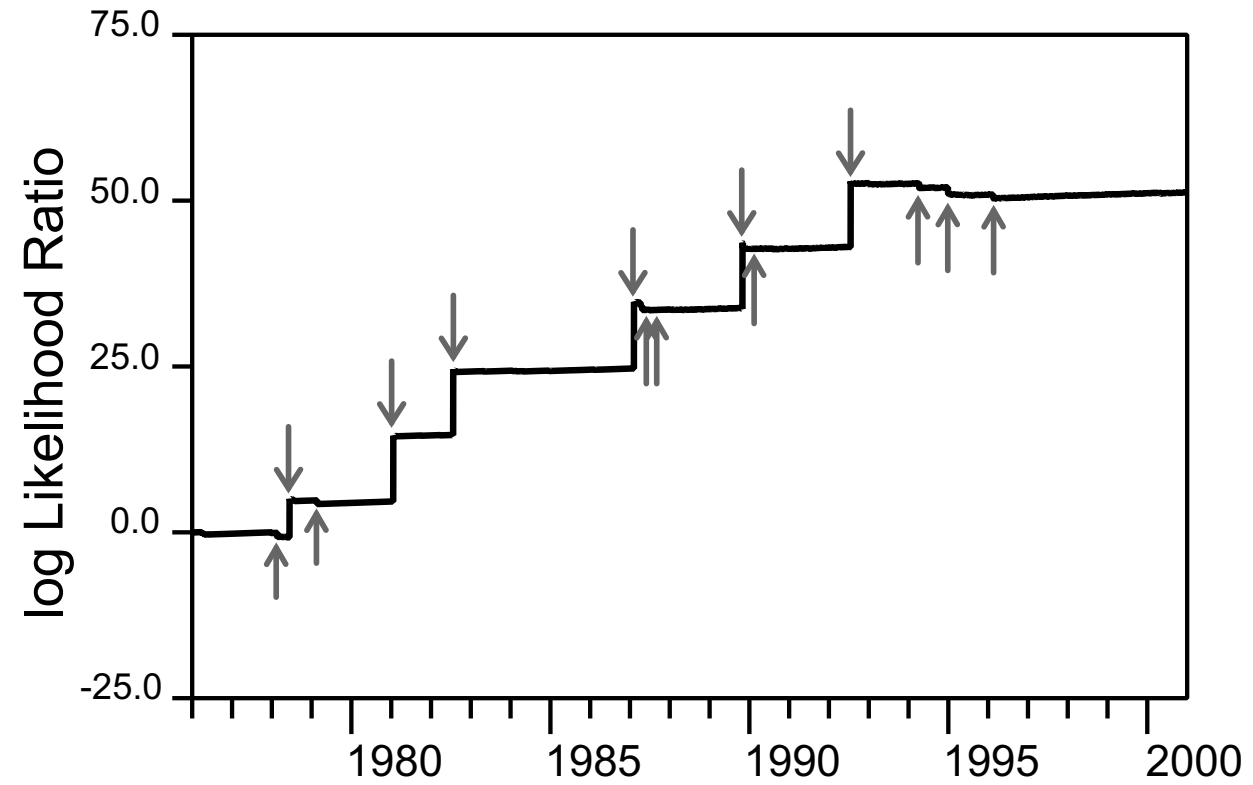

Fig. 4. Log-likelihood ratio and time chart, obtained by retrospectively applying the proposed model to the present dataset. The Poisson model is used as the standard to calculate the likelihood ratio of the proposed model.

\section{Retrospective and Prospective Analyses}

We can measure the spatial distributions of the hazard function immediately before the main shocks retrospectively, and evaluate its performance over time in terms of the loglikelihood ratio. We illustrate the spatial distribution of the hazard here by examining two earthquakes (19 January 1981, 18 July 1992) that exhibited somewhat high probability gains. The areas of probability gain greater than
20,000 , which indicate observation of more than two foreshocks, are wider than that of the spatial window $(20 \mathrm{~km}$ in radius) in Figs. 3(a) and 3(b), which implies increased activity of potential foreshocks. Figure 4 illustrates the temporal changes in the log-likelihood ratio, where the stationary Poisson model is used as the standard. We observed six upward steps, which corresponds to six earthquakes preceded by potential foreshocks, attaining a large probability gain. 
We observed a slight loss in the performance chart for the other eight earthquakes, since the probability gain without potential foreshocks is a few tens of percent. The performance chart exhibited a constant build-up over time with no signs of anomalous features, except for a few recent cases.

We prospectively apply the model to data from January 2001 to September 2003. During that period, the Tokachioki Earthquake with magnitude of 8.0 occurred on the 26th of September, 2003, which is the only event to satisfy our target criteria. Figure 5 illustrates the changes in log-likelihood ratio for this period, is the same way as in Fig. 4. Although the scale is different from that in Fig. 4, several small downward steps correspond to times of potential foreshocks. A notable downward step (immediately before the right end) is originated from the fact that no potential foreshocks preceded the Tokachi-oki earthquake. Since a small proportion of main shocks are preceded by potential foreshocks, it is not unreasonable to observe a small loss in the performance chart from a case study including a small number of main shocks.

\section{Long-term Hazard}

As mentioned earlier, the Earthquake Research Committee $(2000,2002)$ has published the long-term probability of a large earthquake in the offshore area from Sanriku to Boso. The study area is depicted in Fig. 6. In this region, inter-plate earthquakes caused by the relative motion between the $\mathrm{Pa}$ cific plate and North American plate are frequently observed. The long-term probability is calculated using two types of models. The first type, renewal process models, is adopted for inter-plate earthquakes based on the concept of characteristic earthquake (Schwartz and Coppersmith, 1984). Otherwise, a stationary Poisson process model is used. In some regions, the long-term probability is calculated for both interplate earthquakes and other earthquakes. We shall attempt later to enhance the short-term probability by combining the model of potential foreshock with the long-term probability. A short-term probability so obtained is dependent on whether it is characteristic or not. Since it is not possible to distinguish the type of the earthquake from the data on potential foreshocks, it is reasonable that we accommodate the case of the higher probability, observing potential foreshocks. For this reason, we select the largest long-term probability, in this paper when long-term probabilities for two or more types in the same area were estimated. Table 4 lists models and model parameters used for the hazard calculation (as of July 1, 2003), and long-term probability published by Earthquake Research Committee (2000, 2002).

\section{Synthesis of an Earthquake Probability}

The results of potential foreshock activity were utilized to enhance a shorter-term probability using the following procedure. It is assumed that the hypocenter (starting point of the fracture) of each characteristic earthquake has the same potential to be at any location in source region. The hazard function, which changes only with time, is obtained from the long-term probability model (the lognormal distribution model, the Brownian model, or Poisson model, see e.g., Utsu, 1984; Matthews et al., 2002). The hazard at a certain time point is divided by the total source volume, where an uncertainty of $40 \mathrm{~km}$ width for the focal depth is assumed at any point; this yields a hazard function, $\lambda_{c}(s)$. The hazard function becomes even greater if the hypocenter is specified more accurately. Observing the $N_{f}$ potential foreshocks enables the hazard function of a characteristic earthquake (given $N_{f}$ ) to be represented as illustrated in Eq. (5) by the Bayes theorem.

$$
\lambda_{c}\left(s \mid N_{f}\right) d s=\frac{P\left(N_{f} \mid E_{c}\right) \lambda_{c}(s) d s}{P\left(N_{f} \mid E_{c}\right) \lambda_{c}(s) d s+P\left(N_{f} \mid \overline{E_{c}}\right)\left\{1-\lambda_{c}\left(E_{c}\right) d s\right\}}
$$

It is reasonable to assume that

$$
P\left(N_{f} \mid E_{c}\right) \lambda_{c}(s) d s\left\langle\left\langle P\left(N_{f} \mid \overline{E_{c}}\right)\left\{1-\lambda_{c}\left(E_{c}\right) d s\right\},\right.\right.
$$

and

$$
\lambda_{c}\left(E_{c}\right) d s\langle\langle 1
$$

Thus,

$$
\lambda_{c}\left(s \mid N_{f}\right) d s=\frac{P\left(N_{f} \mid E_{c}\right)}{P\left(N_{f} \mid \overline{E_{c}}\right)} \lambda_{c}(s) d s
$$

is obtained. $P\left(N_{f} \mid E_{c}\right)$ is the probability that $N_{f}$ potential foreshocks will be observed prior to the characteristic earthquake. Though a few examples of characteristic earthquakes are included in the dataset of the present study, it is not possible to determine $P\left(N_{f} \mid E_{c}\right)$ from only these events. Available data are insufficient to discuss the difference in conditional distributions of foreshocks between a characteristic earthquake and the earthquakes $(M \geq 6.5)$ included in the present paper. Therefore, we tentatively assume that

$$
P\left(N_{f} \mid E_{c}\right)=P\left(N_{f} \mid E\right) .
$$

The background density in a characteristic earthquake is similar to that in the present study, and thus the relation between the two background distributions is presented as follows.

$$
P\left(N_{f} \mid \overline{E_{c}}\right)=P\left(N_{f} \mid \bar{E}\right) .
$$

Therefore, the probability of each characteristic earthquake, conditional on observing $N_{f}$ potential foreshocks, is given by the product of the probability gain and the probability derived from the long-term model.

$$
\lambda_{c}\left(s \mid N_{f}\right) d s=\frac{P\left(N_{f} \mid E\right)}{P\left(N_{f} \mid \bar{E}\right)} \lambda_{c}(s) d s .
$$

The hazard in a particular region is obtained by integrating the above equation with respect to space variables.

\section{Discussion}

Foreshocks, as defined here, did not occur before the Tokachi-oki earthquake of September 26, 2003. This follows the recent three main shocks without a potential foreshock after the July 18, 1992 event as indicated by the retrospective test in Fig. 4. Of those three earthquakes, the epicenters of two earthquakes are located in the northern part of the study area, and the Tokachi-oki earthquake also occurred also in this part. This may be considered due to the regionality of the clustering feature of earthquakes. For example, it was reported that a regional variation exists for foreshock activity (Mogi, 1963; Ogata, 1996). Mogi (1963) reported that the clustering feature of earthquakes is related to the homogeneous or inhomogeneous state of geology and/or the stress 


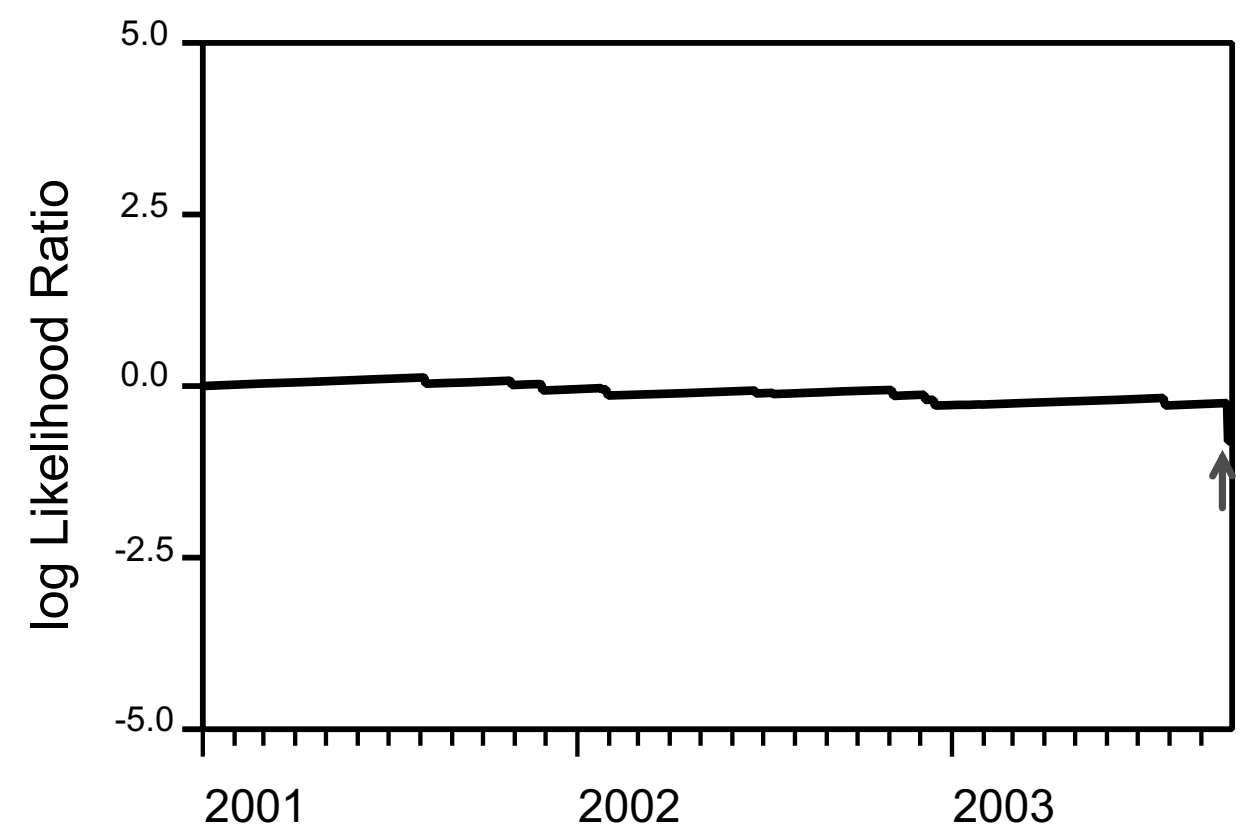

Fig. 5. Log-likelihood ratio and time chart obtained by a prospective test applying the model to data for the period from January 1 , 2001 to September 30 , 2003. Same as Fig. 4 but for this period. Note the difference in both scales.

Table 4. Long-term probabilities of 10 yrs, models, and hazard in respective regions. P, Ln, and B in the Model column indicate Poisson, log-normal (Utsu, 1984), and Brownian (Matthew et al., 2003) models. T indicates mean recurrent intervals. The Brownian model for region No. 2 uses 104.5 and 0.19 for recurrence interval and aperiodicity parameters. The lognormal model for region No. 3 uses 3.60 and 0.177 for the recurrence interval and its variance. Hazard 1 indicates the number of hazards for respective regions per year. Hazard 2 indicates hazards for a unit space-time volume in units of cubic kilometers by day in respective regions.

\begin{tabular}{|c|c|c|c|c|c|c|c|}
\hline & & M & $10 y r s$ & Model ${ }^{*}$ & $\begin{array}{c}\mathrm{T} \\
(\mathrm{yrs})\end{array}$ & $\begin{array}{l}\text { Hazard1 } \\
\text { (N/year) } \\
\end{array}$ & $\begin{array}{c}\text { Hazard2 } \\
\left(\mathrm{N} / \mathrm{km}^{3} \quad \text { day }\right) \\
\end{array}$ \\
\hline 1. & $\begin{array}{l}\text { Northern off-shore of Sanriku } \\
\text { Non-Characteristic Eq. }\end{array}$ & 7.1 & 60 & $\mathrm{P}$ & 11.3 & 0.0885 & $3.43110^{-10}$ \\
\hline 2. & Southern off-shore of Sanriku & 7.7 & 40 & $\mathrm{~B}$ & 104.5 & 0.04533 & $4.34910^{-10}$ \\
\hline 3. & Off-shore of Miyagi Prefecture & 7.5 & 30 & $\mathrm{LN}$ & 36.5 & 0.00922 & $7.28910^{-11}$ \\
\hline 4. & Off-shore of Fukushima Prefecture & 7.4 & 2 & $\mathrm{P}$ & 400 & 0.0025 & $1.85010^{-11}$ \\
\hline 5 . & Off-shore of Ibaraki Prefecture & 6.8 & 50 & $\mathrm{P}$ & 15.5 & 0.06452 & $6.03810^{-10}$ \\
\hline 6. & $\begin{array}{l}\text { Sanriku North - Boso } \\
\text { Tsunami Eq. }\end{array}$ & 8.2 & 7 & $\mathrm{P}$ & 133.3 & 0.0075 & $8.81110^{-12}$ \\
\hline
\end{tabular}

field. Mogi's results obtained from foreshock and aftershock sequences in Japan, show that this study area essentially belongs to the single group of geologic structures defined in his study. Likewise, compared with other areas in Japan, his results shows that a main shock with foreshocks is generally frequent in the present study area. However, details differ a little from one part of the study area to another, as indicated by Ogata (1996). Actually, three main shocks (Nos. 3, 14, and 15 in Table 1) near 40 degrees in latitude were not preceded by foreshocks. The Tokachi-oki earthquake, which occurred in the prospective test period, follows these. This regionality could reflect either differences in geology and physics underlying the earthquake preparation process or inaccuracies of hypocenter determination. It might be possibly due to other reasons such as changes in the JMA network, its processing system and others. Nevertheless, we cannot reach a definite conclusion based on only one sample of the prospective test after January 1, 2001. As shown in Fig. 4, the cumulative value of the log-likelihood ratio showed a loss of up to 2 from December 31, 2000, to January 01, 1993. A maximum value of 0.6 is lost with the Tokachi-oki earthquake of 2003. Considering this, the proposed model cannot yield a conclusive determination. Since there are eight earthquakes without a foreshock (among 14 examples), the probability is $6 \%$ that a main shock will occur five times in succession without a foreshock, and the log-likelihood ratio is reduced by 3 in this case. The probability that a main shock will occur without a foreshock seven times in succession is $2 \%$, and the loss is estimated at 4 . Therefore, if a loss over 5 is observed, the model should be rejected. However, the log-likelihood ratio increases by about 10 when we observe a main shock with foreshocks. The probability of occurrence of such an event is significant, since an earthquake with foreshocks is observed in 6 of 14 cases. Therefore, the possibility of exceeding this by chance is high if the threshold for the model acceptance is set at a gain of 5. To accept the model, it is reasonable to consider a ratio of main shocks accompanied by foreshocks to the total, rather than a gain in likelihood (Evison and Rhoades, 1997). The proposed model requires several main shocks for a conclusive judgment. 


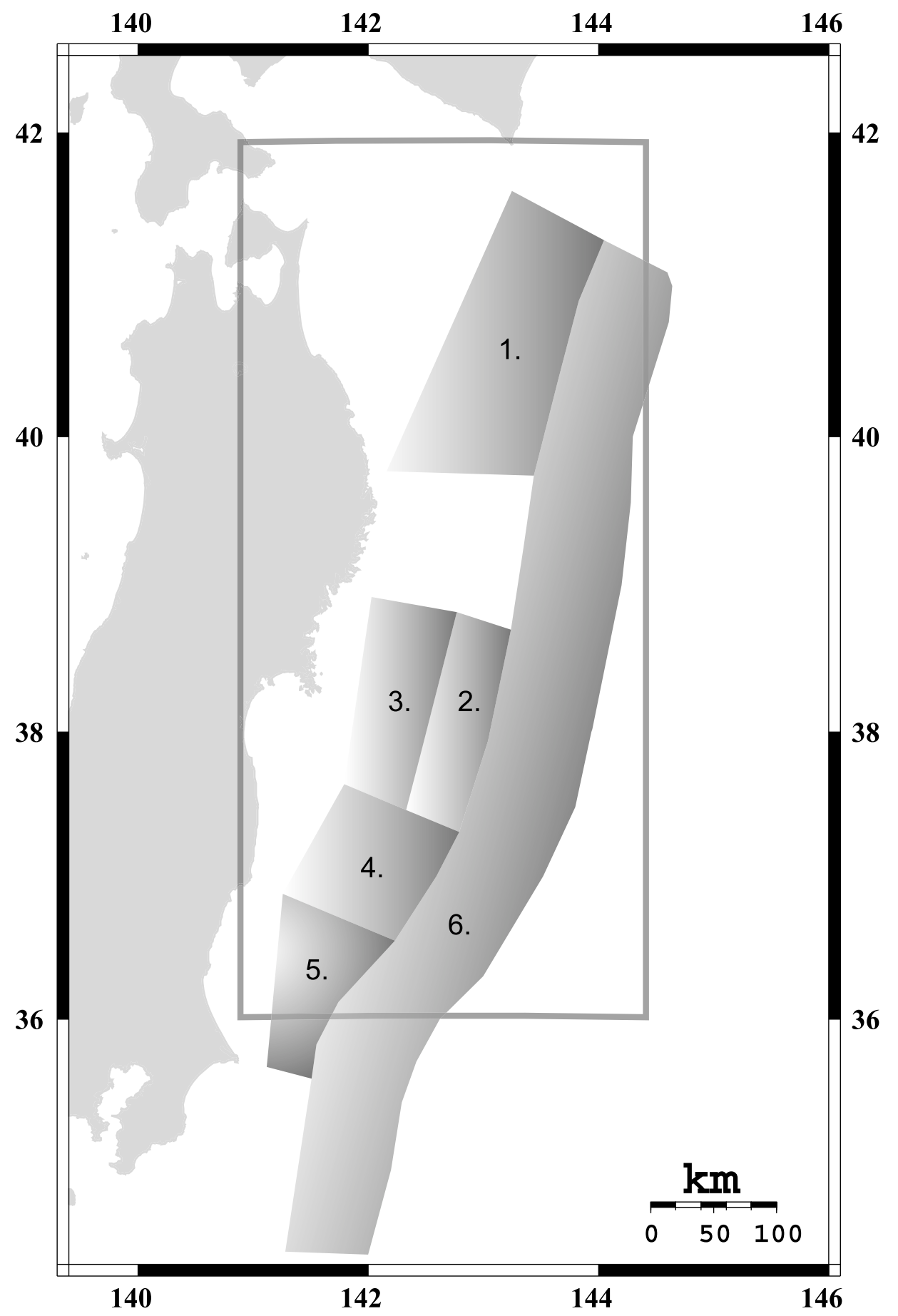

Fig. 6. Zoning for long-term probability estimation (after Earthquake Research Committee, 2002).

For practical use of this method, it is important to consider a false alarm rate. In the scheme of this method, however, concepts of issuing alarms or space-time volumes in alarm are not clear, though high-risk parts are defined. The retrospective analysis estimated that parts of the highest-risk share a space-time volume of 1,500,000 days $\times \mathrm{km}^{3}$. Within this volume, we observed five earthquakes with magnitudes 6.5 and larger. A representative space-time volume of the case was considered to be about $30,000 \mathrm{~km}^{3}$, since a part of the highest-risk covers a spherical volume of $20 \mathrm{~km}$ radius and 1 day duration, with two potential foreshocks being observed at one time and in the same location. Such spherical volumes were observed about 50 times in the highest-risk part. Five out of 50 volumes contain earthquakes with magnitudes 6.5 and larger, and the rest of the volumes do not contain earthquakes. Thus, an expected false alarm rate could be roughly estimated at about 0.9 . This might be a little high for the practical use of the method.

In the Earthquake Research Committee (2002) report, there are cases in which more than two types of earthquakes are assumed in one region. In principle, it is possible to distinguish one type from another based on the location of a potential foreshock in the region. Since the source area of a characteristic earthquake is specified to some extent, earth- 
quakes occurring near this area can be regarded as potential foreshocks of the characteristic earthquake. However, in practice this is difficult for the following two reasons. First, hypocenters of intra-plate earthquakes, which are not characteristic earthquakes, could sometimes be located near a plate boundary, i.e., at a distance that is comparable to or less than the spatial distance between potential foreshocks and their main shock. In our case, its representative length is $20 \mathrm{~km}$. Secondary, location accuracy of potential foreshocks becomes a problem. In the present paper, the hazard is estimated assuming a depth range of $40 \mathrm{~km}$. If this were reduced to a half, the hazard would become twice as large as the present estimate, and the synthetic probability would also double. However, potential foreshocks, which sometimes occur in an area far from the observation network on land, cannot always be located with sufficient accuracy. The absolute location is not always determined as accurately as the estimated source volume of the characteristic earthquake, even if the relative locations of the hypocenters of the characteristic earthquake and potential foreshocks are sufficiently accurate for the present purpose. Aoki et al. (2003) compared hypocenters of earthquakes off Tokai that are routinely determined using only observation sites on land, with those determined by both land and ocean bottom seismometers. They demonstrated large differences between them, especially in depth. For these reasons, it is practically difficult to distinguish the earthquake type based on the location of the potential foreshock, without nearby observation sites such as ocean bottom seismometers. Considering this point, a width of $40 \mathrm{~km}$ was used as the specified range of depth in the present case.

This paper combind potential foreshocks and long-term probability to develop a technique for the probabilistic prediction of a large earthquake anticipated from offshore Sanriku to Boso. Since the asociated probability gain (calculated from the potential foreshock) becomes up to 20,000 , the imminent probability is of a practical and promising value. The model is being verified (by an on-line real-time process) using the data from 2001 to the present. Before the Tokachioki earthquake (September 26, 2003), however, there was no foreshock, and no sudden rise in the probability was observed. We must wait for more main shocks to establish or reject the model's validity.

Acknowledgments. Comments by Keiit Aki, Anshu Jin and an anonymous reviewer have greatly helped to improve this article.

\section{References}

Aki, K., A probabilistic synthesis of precursory phenomena, in Earthquake Prediction, edited by D. W. Simpson and P. G. Richards, pp. 566-574, AGU, 1981.

Aoki, K., A. Yamazaki, Y. Yoshida, Y. Ishikawa, M. Abe, S. Masaka, and H. Takeuchi, Seismicity off Tokai observed by ocean bottom seismographs-Relation of the JMA cataloue and a result of the 2003 observation-, Programme and Abstracts, SSJ 2003 Fall Meeting, A053, 2003 (in Japanese).

Console, R. and M. Murru, A simple and testable model for earthquake clustering, J. Geophys. Res., 106, 8699-8711, 2001.

Earthquake Research Committee, the Headquarters for Earthquake Research Promotion, Government of Japan, Long-term evaluation of earthquakes in the sea off Miyagi Prefecture, 2000 (as of July 1, 2003, in Japanese).

Earthquake Research Committee, the Headquarters for Earthquake Research Promotion, Government of Japan, Long-term evaluation of earthquakes in the sea off from Sanriku to Boso, 2002 (as of July 1, 2003, in Japanese).

Evison, F. F. and D. A. Rhoades, The precursory earthquake swarm in New Zealand: Hypothesis test II, N. Z. J. Geol. Geophys., 40, 537-547, 1997.

Imoto, M., Application of the stress release model to the Nankai earthquake sequence, southwest Japan, Tectonophysics, 338, 287-295, 2001.

Imoto, M., Use of potential foreshocks to amplify short term probabilities of recurrent large earthquakes along the Japan trench, Zisin II, 56, 2003 (in Japanese).

Maeda, K., The use of foreshocks in probabilistic prediction along the Japan and Kuril trenches, Bull. Seism. Soc. Am., 86, 242-254, 1996.

Matthews, M. V., W. L. Ellsworth, and P. A. Reasenberg, A Brownian Model for Recurrent Earthquakes, Bull. Seism. Soc. Am., 92, 2233-2250, 2002.

Meteorological Research Institute, Forecast of earthquakes far off Sanriku Coast, July, 1992-Probability Estimation of Earthquake Occurrence from the Viewpoint of Successiveness of Seismic Activity-, Report of the Coordinating Committee for Earthquake Prediction, 49, 60-66, 1993 (in Japanese).

Mogi, K., Some discussions on aftershocks, foreshocks and earthquake swarms - the fracture of a semi-infinite body caused by an inner stress origin and its relation to the earthquake phenomena (third paper), Bull. Earthq. Res. Inst., 41, 615-658, 1963.

Ogata, Y, Statistical discrimination of foreshocks from other earthquake clusters, Geophys. J. Int., 127, 17-30, 1996.

Rhoades, D. A. and F. F. Evison, On the reliability of precursors, Phys. Earth Planet. Inter., 58, 137-140, 1989.

Sakamoto, Y., M. Ishiguro, and G. Kitagawa, Akaike Information Criterion Statistics, D. Reidel, Dordrecht, 290 pp, 1983.

Schwartz, D. P. and K. J. Coppersmith, Fault behavior and characteristic earthquakes: Examples from the Wasatch and San Andreas fault zones, $J$. Geophys. Res., 89, 5681-5698, 1984.

Utsu, T., Probalities in earthquake prediction, Zisin II, 30, 179-185, 1977 (in Japanese).

Utsu, T., Probabilities in earthquake prediction (the second paper), Bull. Earthq. Res. Inst., 57, 499-524, 1982 (in Japanese).

Utsu, T., Estimation of parameters for recurrence models of earthquakes, Bull. Earthq. Res. Inst., 59, 53-66, 1984.

M. Imoto (e-mail: imoto@bosai.go.jp) 